\title{
Carbonation and the Urey reaction ${ }^{\circ}$
}

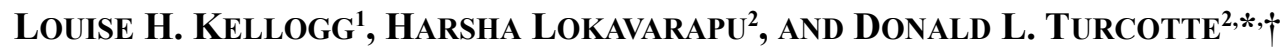

\author{
${ }^{1}$ Department of Earth and Planetary Science, University of California, Davis, 1 Shields Avenue, Davis, California 95616, U.S.A. \\ Orcid 0000-0001-5874-0472 \\ ${ }^{2}$ Department of Earth and Planetary Science, University of California, Davis, 1 Shields Avenue, Davis, California 95616, U.S.A.
}

\begin{abstract}
There are three major reservoirs for carbon in the Earth at the present time, the core, the mantle, and the continental crust. The carbon in the continental crust is mainly in carbonates (limestones, marbles, etc.). In this paper we consider the origin of the carbonates. In 1952, Harold Urey proposed that calcium silicates produced by erosion reacted with atmospheric $\mathrm{CO}_{2}$ to produce carbonates, this is now known as the Urey reaction. In this paper we first address how the Urey reaction could have scavenged a significant mass of crustal carbon from the early atmosphere. At the present time the Urey reaction controls the $\mathrm{CO}_{2}$ concentration in the atmosphere. The $\mathrm{CO}_{2}$ enters the atmosphere by volcanism and is lost to the continental crust through the Urey reaction. We address this process in some detail. We then consider the decay of the Paleocene-Eocene thermal maximum (PETM). We quantify how the Urey reaction removes an injection of $\mathrm{CO}_{2}$ into the atmosphere. A typical decay time is $100000 \mathrm{yr}$ but depends on the variable rate of the Urey reaction.
\end{abstract}

Keywords: Urey reaction, deep carbon, chemical geodynamics, carbonation; Earth in Five Reactions: A Deep Carbon Perspective

\section{INTRODUCTION}

The continental crust is a major reservoir for carbon in the Earth. A major question in geology is the origin of the carbon, principally in calcium carbonates. The first successful attempt to explain the origin of calcium carbonates (limestones, marbles) in the continental crust was given by Urey (1952). The basic equation he gave was of the form

$$
\mathrm{CaSiO}_{3}+\mathrm{CO}_{2} \leftrightarrow \mathrm{CaCO}_{3}+\mathrm{SiO}_{2}
$$

He proposed that atmospheric $\mathrm{CO}_{2}$ combines with a calcium silicate to generate a calcium carbonate plus silica. A direct quote from his paper states: "As carbon dioxide was formed it reacted with silicates to form limestone. Of course, the silicates may have been a variety of minerals, but the presence of $\mathrm{CO}_{2}$ was always kept at a low level by this reaction or similar reactions just as it is now."

In the current literature an expanded version of the Urey reaction is given (Blättler and Higgins 2017). To include the role of acid rain the Urey reaction takes the form

$$
\begin{aligned}
& \mathrm{CaSiO}_{3}+2 \mathrm{CO}_{2}+\mathrm{H}_{2} \mathrm{O} \rightarrow \mathrm{Ca}^{2+}+2 \mathrm{HCO}_{3}^{-}+\mathrm{SiO}_{2} \\
& \rightarrow \mathrm{CaCO}_{3}+\mathrm{SiO}_{2}+\mathrm{CO}_{2}+\mathrm{H}_{2} \mathrm{O} .
\end{aligned}
$$

The carbonation takes place when carbon dioxide (carbonic acid) in acid rain dissolves calcium silicate (wollastonite) sediments to give calcium, bicarbonate, and silica. The resulting calcium and bicarbonate ions flow in rivers to the oceans where either organic or inorganic precipitation produces the calcium carbonate.

The three large reservoirs for carbon in the Earth at the present

*E-mail: dlturcotte@ucdavis.edu

$\uparrow$ Special collection papers can be found online at http://www.minsocam.org/MSA/ AmMin/special-collections.html.

of Open access: Article available to all readers online. time are the core, mantle, and continental crust. We assume that the core is an isolated reservoir and neglect its role. About $1 \%$ of the carbon in the Earth is in the continental crust. Wedepohl (1995) has given a comprehensive study of the composition of the continental crust with an emphasis on carbon. He gives an estimate for the total mass of carbon $(c)$ in the continental crust $(c c)$ at the present time $(p)$ of ${ }^{c} M_{c c p}=4.2 \times 10^{7}$ Gt. Hayes and Waldbauer (2006) have reviewed the literature on carbon in the continental crust and suggest that it may be as high as ${ }^{c} M_{c c p}=10^{8} \mathrm{Gt}$. DePaolo (2015) gives a range of 6 to $7 \times 10^{7} \mathrm{Gt}$. In this paper, we take a representative value to be ${ }^{c} M_{c c p}=5 \times 10^{7} \mathrm{Gt}$. The mass of carbon in the ocean is about a factor of $10^{3}$ less than the mass of carbon in the continental crust (Houghton 2007).

Urey $(1952,1956)$ clearly recognized that the reaction he proposed would efficiently remove $\mathrm{CO}_{2}$ from the Earth's atmosphere, but at that time little was known about the early atmosphere. Although the mass of carbon in the atmosphere today is small $(850 \mathrm{Gt})$, the mass may have been much higher in the past. One of the major differences between Venus and the Earth is atmospheric composition. The atmospheric pressure on Venus is about a factor of 100 greater than the atmospheric pressure on Earth and is $96 \%$ carbon dioxide. The mass of carbon in the Venus atmosphere ( $a$ ) at the present time $(p)$ is ${ }^{c} M_{a p}=1.28 \times 10^{8}$ Gt. Scaling the atmospheric carbon masses to the overall masses of Venus and the Earth gives an estimate of the mass of carbon (c) in the early atmosphere $(t=0)$ of the Earth. The estimated value is ${ }^{c} M_{a 0}=1.57 \times 10^{8} \mathrm{Gt}$ (Kasting and Ackerman 1986).

\section{CARBON FROM THE ATMOSPHERE TO THE CONTINENTAL CRUST}

One hypothesis for the origin of the carbon in the continental crust is that it was extracted directly from the atmosphere relatively early in Earth's history. The estimated mass of carbon (c) in the early atmosphere (a) given above, ${ }^{c} M_{a 0}=1.57 \times 10^{8} \mathrm{Gt}$, 
is substantially larger than the total estimated carbon in the continental crust given above, ${ }^{c} M_{c c p}=5 \times 10^{7} \mathrm{Gt}$. The hypothesis of direct extraction from the atmosphere has been discussed in some detail by Kramers (2002) and by Lowe and Tice (2004).

The basic hypothesis is that the mass flux of carbon from the atmosphere to the continental crust, ${ }^{c} J_{a-c c}$, is controlled by the availability of calcium silicates. In order for the Urey reaction to extract $\mathrm{CO}_{2}$ from the atmosphere the early Earth must have had continental crust to generate surface deposits of calcium silicate. In addition, the Earth must have had oceans in order for the acid rain to catalyze the Urey reaction between atmospheric $\mathrm{CO}_{2}$ and the service deposits of calcium silicates. Little data are available for timing the initiation of the extraction of $\mathrm{CO}_{2}$ from the atmosphere. We will assume that the process begins at a time $t_{0}$ after the early bombardment and the solidification of the magma ocean at about $4.4 \mathrm{Ga}$. We further assume that the Urey reaction extracted carbon from the atmosphere at a constant rate ${ }^{c} J_{a-c c}$ until the concentration of $\mathrm{CO}_{2}$ in the atmosphere was reduced to a very low level. During the time, $t_{0}<t<t_{0}+\tau_{a-c c}$, the Urey reaction extracts atmospheric carbon to the continental crust. We will specify the mass of carbon extracted from the atmosphere and obtain

$$
{ }^{c} J_{a-c c}=\frac{{ }^{c} M_{a 0}}{\tau_{a-c c}} .
$$

We assume that the mass of carbon in the atmosphere ${ }^{c} M_{a}$ decreases linearly in time from ${ }^{c} M_{a 0}$ to zero during the time period $\tau_{a-c c}$ and the mass of carbon in the continental crust increases linearly in time.

Assuming all the carbon in the continental crust ${ }^{c} M_{c c p}$ was extracted from the atmosphere the dependence on time is given by

$$
\begin{aligned}
& { }^{c} M_{c c}=00 \leq t \leq t_{0} \\
& { }^{c} M_{c c}={ }^{c} M_{c c p}\left[\left(t-t_{0}\right) /\left(\tau_{a-c c}\right)\right] t_{0} \leq t \leq t_{0}+\tau_{a-c c} \\
& { }^{c} M_{c c}={ }^{c} M_{c c p} t_{0}+\tau_{a-c c} \leq t \leq t_{p}
\end{aligned}
$$

Taking ${ }^{c} M_{c c p}=5 \times 10^{7} \mathrm{Gt}, t_{0}=1 \mathrm{Gyr}$, and $\tau_{a-c c}=1 \mathrm{Gyr}$, the dependence of ${ }^{c} M_{c c}$ on $\mathrm{t}$ is given in Figure 1. The required flux of carbon from the atmosphere to the continental crust is ${ }^{c} J_{a-c c}=50$ $\mathrm{Mtyr}^{-1}$. It must be emphasized that the value of $\tau_{a-c c}$ is uncertain and the flux ${ }^{c} J_{a-c c}$ is expected to have considerable variability in time. However it is quite clear that the extraction of carbon from the atmosphere to the continental crust would have been carried out early in Earth's history.

\section{REMOVAL OF THE VOLCANIC ADDITION OF CARBON TO THE ATMOSPHERE}

When excess carbon in the atmosphere has been depleted by the Urey reaction an approximate steady-state balance is established between the volcanic input of carbon into the atmosphere and the extraction by the Urey reaction. We approximate this balance by the relationship

$$
c J_{a-c c}=\frac{c M_{a}}{\tau_{u}} .
$$

where ${ }^{c} J_{a-c c}$ is the rate of volcanic input of carbon into the atmosphere. We assume that this extraction rate is constant and

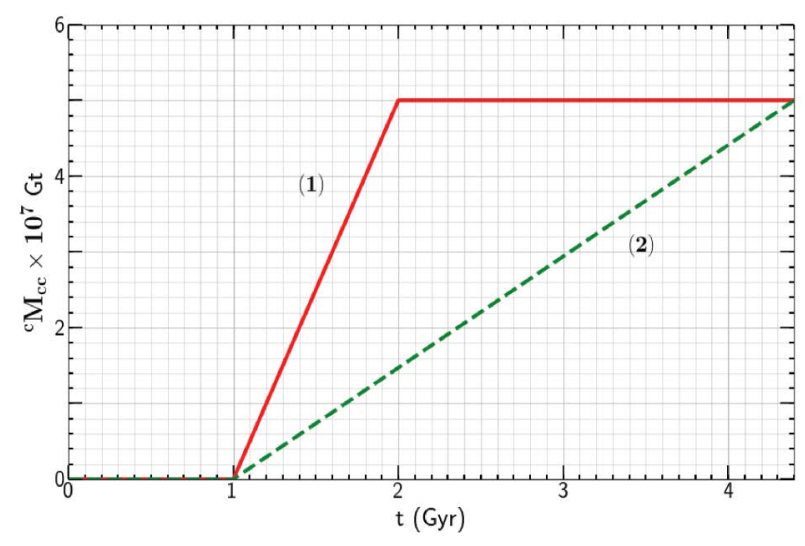

FIGURE 1. Dependence of the mass of carbon in the continental crust ${ }^{c} M_{c c}$ on time. Two limiting models are given for adding the present mass ${ }^{c} M_{c c p}=5 \times 10^{7} \mathrm{Gt}$. (1) Addition from the atmosphere beginning at $t_{0}=1$ Gyr. All atmospheric carbon is transferred in $\tau_{a-c c}=1 \mathrm{Gyr}$ at a constant flux ${ }^{c} J_{a-c c}=50 \mathrm{Mtyr}^{-1}$. (2). Addition from the mantle beginning at $t_{0}=1$ Gyr. Carbon is added at a constant flux ${ }^{c} J_{m-c c}=14.7 \mathrm{Mtyr}^{-1}$ to the present.

is proportional to the mass of carbon in the atmosphere ${ }^{c} M_{a}$. The characteristic time $\tau_{u}$ takes account of the rate at which acid rain can interact with calcium silicate sediments, and although we assume that $\tau_{u}$ is constant it clearly can be a function of time.

A comprehensive model for the variability of atmospheric $\mathrm{CO}_{2}$ over Phanerozoic times has been given by Berner and Kothavala (2001). This model, GEOCARB III, is complex and involves both organic and inorganic processes. Transport of carbon between the atmosphere, oceans, and continental crust is quantified on the million year timescale. The balance is dominated by the exchange of carbon between carbonates in the continental crust and carbon in the surficial reservoirs (oceans and atmosphere) and organic carbon (Berner and Caldeira 1997). When erosion is high, the Urey reaction extracts $\mathrm{CO}_{2}$ from the atmosphere adding carbonates to the continental crust. High erosion rates are associated with low sea level and large continental areas. When erosion is low, the Urey reaction operates in the opposite direction (from right to left in Eq. 1) with carbonates decomposing to give $\mathrm{CO}_{2}$. An example of this metamorphic process is the subduction of carbonate sediments and the generation and return to the atmosphere of $\mathrm{CO}_{2}$ in subduction zone volcanics (Frezzotti et al. 2011).

The present mass of carbon in the atmosphere is $860 \mathrm{Gt}$ (400 ppmv $\mathrm{CO}_{2}$ ), but this is not a quasi-equilibrium value because of the anthropogenic addition at high fluxes (3.5 $\mathrm{Gtyr}^{-1}$ ). We will take the 1900 value of $650 \mathrm{Gt}$ (300 ppmv $\mathrm{CO}_{2}$ ) as the present equilibrium value. This is a typical value for the current glacial epoch (0 to $50 \mathrm{Ma})$. Values given by the GEOCARB III Model are generally consistent with observations (Royer 2014). Between 50 and $250 \mathrm{Ma}$, the average values were about $3000 \mathrm{Gt}$. During the major glacial epoch between 250 and $350 \mathrm{Ma}$ low observed values near $650 \mathrm{Gt}$ are found. Between 350 and $550 \mathrm{Ma}$, values were considerably higher, typically near $10000 \mathrm{Gt}$. This variability reflects variations in both of the variables in Equation 3, the volcanic flux ${ }^{c} J_{a-c c}$ into the atmosphere and the characteristic time $\tau_{u}$. 


\section{Carbon from the mantle to the continental crust}

The second hypothesis for the origin of the carbon in the continental crust is that it comes from the mantle. If the volcanic flux of carbon out of the mantle at ocean ridges and hot spots exceeds the carbon lost to the mantle at subduction zones, the difference will be added to the continental crust. Some of the volcanic carbon input will enter the atmosphere and will be transferred to the continental crust through the Urey reaction. However, some will enter the oceans and will be converted directly to carbonates without entering the atmosphere.

Rates of carbon loss from the mantle by volcanism and lost by subduction will certainly vary over geologic time, but the variations are uncertain. Again, we assume that the plate tectonic processes required for carbon transfer began at a time $t_{0}$ after the solidification of the magma ocean at about $4.5 \mathrm{Ga}$. We further assume that the transfer of carbon out of the mantle has been at a constant rate ${ }^{c} J_{m-c c}$ until the present time $t_{p}$. Assuming all the carbon in the continental crust has been extracted from the mantle, the dependence on time is given by

$$
\begin{aligned}
& { }^{c} M_{c c}=00 \leq t \leq t_{0} \\
& { }^{c} M_{c c}={ }^{c} M_{c c p}\left[\left(t-t_{0}\right) /\left(t_{p}-t_{0}\right)\right] t_{0} \leq t \leq t_{\mathrm{p}}+\tau_{a-c c} .
\end{aligned}
$$

The mass of carbon in the continental crust increases linearly in time over the period $t_{0}$ to $t_{p}$. The required flux of carbon from the mantle to the continental crust is given $\mathrm{y}$

$$
c J_{m-c c}=\frac{{ }^{c} M_{c c p}}{t_{p}-t_{0}} .
$$

Taking ${ }^{c} M_{c c p}=5 \times 10^{7} \mathrm{Gt}, t_{0}=1 \mathrm{Gyr}$, and $t_{p}=4.4 \mathrm{Gyr}$ the dependence of ${ }^{c} M_{c c}$ on $t$ is given in Figure 1. The required flux of carbon from the mantle to the continental crust is ${ }^{c} J_{m-c c}=14.7 \mathrm{Mtyr}^{-1}$.

We next consider the estimate for the present loss of carbon from the mantle to the atmosphere. Dasgupta and Hirschmann (2010) have summarized the available data on the loss of carbon from the mantle to the surface reservoirs and give values in the range ${ }^{c} J_{m-s}=36 \pm 24 \mathrm{Mtyr}^{-1}$. Just as carbon is lost from the mantle by volcanism, carbon is returned to the mantle by subduction. A detailed study of carbon fluxes at subduction zones has been given by Kelemen and Manning (2015). These authors suggest that the downward flux of carbon at global subduction zones is $53 \pm 13 \mathrm{Mtyr}^{-1}$. However a substantial fraction of this carbon never makes it to the mantle due to subduction zone volcanism. They suggested that $24 \pm 24 \mathrm{Mtyr}^{-1}$ reach the mantle. Clearly it is quite possible that all the carbon in the continental crust could have come from the mantle. This conclusion was also given by Hayes and Waldbauer (2006).

In Figure 1 we give examples of the two limiting cases, the carbon in continental crust comes entirely from the atmosphere and the carbon comes entirely from the mantle. In the first case the addition is early in time and in the second case it is more uniform in time. Observations of the mass of carbonates in the continental crust as a function of age could distinguish between the two cases, but the data are sparse. Observations of the mass of carbon in the atmosphere as a function of time could also be a constraint. An example given by Rye et al. (1995) utilizing studies of paleosols concluded that the mass of carbon in the atmosphere at 2.2 to $2.75 \mathrm{Ga}$ was less than $10^{5} \mathrm{Gt}$. The conclusion is that the extraction of a significant mass of carbon from the atmosphere to the continental crust was completed by $t=2$ Gyr. However, how large this mass was is uncertain.

\section{Paleocene-Eocene thermal maximum}

The decay of the Paleocene-Eocene thermal maximum (PETM) can be used to quantitatively constrain the role of the Urey reaction. The PETM was a period of elevated global temperatures $\left(4\right.$ to $5{ }^{\circ} \mathrm{C}$ ) and high atmospheric $\mathrm{CO}_{2}$ beginning at 56.3 $\mathrm{Ma}$, the onset lasted less than $10 \mathrm{Kyr}$ and the subsequent decay lasted about $100 \mathrm{Kyr}$ (Mclnerney and Wing 2011). Storey et al. (2007) have made a strong case for associating the PETM with flood volcanism resulting from the opening of the north Atlantic.

Isotope studies have quantitatively documented the PETM. These studies have been reviewed by Gutjahr et al. (2017). These authors also provided estimates for the carbon content of the atmosphere during the PETM. They suggest that the background carbon mass in the atmosphere before and after the PETM was ${ }^{c} M_{a b}=1400 \mathrm{Gt}$ and the peak mass of carbon was ${ }^{c} M_{a 0}=3050 \mathrm{Gt}$.

We now carry out an analysis of the decay of the PETM due to the loss of $\mathrm{CO}_{2}$ from the atmosphere by the Urey reaction. We extend the balance given in Equation 5 to include the transient removal of carbon from the atmosphere and write

$$
\frac{d c M_{a}}{d t}=c J_{(a-c c) b}-\frac{c M_{a}}{\tau_{u}} .
$$

From Equation 5 the background mass of carbon in the atmosphere is given by

$$
c M_{a b}=\tau_{u} c J_{(a-c c) b} .
$$

We prescribe an initial mass of carbon in the atmosphere at $t=0$, ${ }^{c} M_{a 0}$ and solve Equation 7 taking $\tau_{u}$ to be constant with the result

$$
c M_{a}=\left(c M_{a 0}-c M_{a b}\right) e^{-t / \tau_{u}}+c M_{a b} .
$$

The excess mass of carbon in the atmosphere ${ }^{c} M_{a 0}-{ }^{c} M_{a b}$ decays exponentially as the Urey reaction extracts carbon from the atmosphere.

We next obtain the dependence of atmosphere carbon mass on time during PETM based on the model dependence given in Equation 10. Taking the values ${ }^{c} M_{a b}=1400 \mathrm{Gt}$ and ${ }^{c} M_{a 0}=3050$ Gt with $\tau_{u}=100 \mathrm{kyr}$ the model results are given in Figure 2.

We now return to Equation 9. This result relates the background atmospheric carbon mass ${ }^{c} M_{a b}$ to the background rate of volcanic input of $\mathrm{CO}_{2}$ carbon into the atmosphere ${ }^{c} J_{(a-c) b}$ and the Urey reaction rate $\tau_{u}$. During the PETM we have taken the background carbon mass ${ }^{c} M_{a b}=1400 \mathrm{Gt}$. Taking $\tau_{u}=100 \mathrm{kyr}$ we find from Equation 9 that ${ }^{c} J_{(a-c) b}=14 \mathrm{Mtyr}^{-1}$. This is an independent determination of the volcanic flux of carbon into the atmosphere at that time. As discussed above, we take the present equilibrium mass of carbon in the atmosphere to be ${ }^{c} M_{a b}=6500 \mathrm{Gt}$. Assuming that ${ }^{c} J_{(a-c) b}=14 \mathrm{Mtyr}^{-1}$ we require from Equation 9 that $\tau_{u}=50 \mathrm{kyr}$. This is our estimated relaxation time for a carbon excursion today.

\section{DISCUSSION}

Urey (1952) proposed the Urey reaction, Equation 1, to explain the origin of carbonates in the continental crust. $\mathrm{He}$ argued that the reaction would essentially remove all $\mathrm{CO}_{2}$ from 


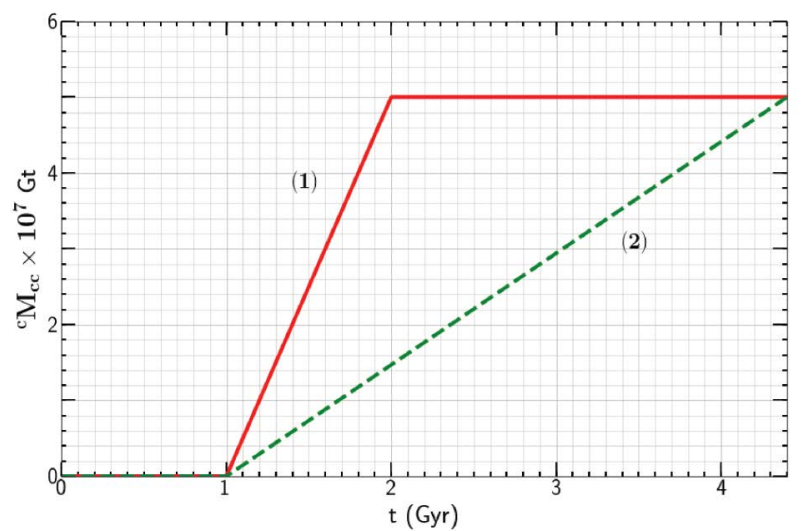

FIGURE 2. Dependence of the atmosphere carbon mass values ${ }^{c} M_{a}$ for the PETM anomaly on time $t_{P E T M}$ relative to the onset of the anomaly. The values are from our relaxation model given in Equation 11 with ${ }^{c} M_{a b}$ $=1400 \mathrm{Gt}$ and ${ }^{c} M_{a 0}=3050 \mathrm{Gt}$ and $\tau_{u}=100 \mathrm{kyr}$.

the atmosphere. It is now accepted that in analogy to Venus, there may have been a large mass of carbon in the Earth's early atmosphere, as much as $10^{8} \mathrm{Gt}$. However, only a fraction of this may have survived the moon forming impact. We give a very simplified model for the extraction of carbon from the atmosphere to the continental curst, taking the extraction rate ${ }^{c} J_{a-c c}$ to be constant. There are basically no constraints on the variation of this rate with time. If a significant fraction of the carbon in the continental crust was extracted from the atmosphere, it is likely that it occurred early in Earth's history as illustrated in Figure 1.

The Urey reaction also controls the equilibrium mass of carbon in the atmosphere after the removal of any large initial concentration. The input of carbon to the atmosphere is from volcanism and we show that the equilibrium mass of carbon in the atmosphere ${ }^{c} M_{a b}$ is proportional to the rate of volcanic injection ${ }^{c} J_{a-c c}$ divided by a characteristic Urey time $\tau_{u}$. We quantify the value of $\tau_{u}$ by studying the observed relaxation of the PaleoceneEocene thermal maximum, which occurred at $56 \mathrm{Ma}$, and the relaxation time is about $\tau_{u}=10^{5}$ yrs.

We also give a simplified model for the extraction of carbon from the atmosphere to the continental crust. If the volcanic loss of carbon from the mantle by volcanism exceeds the return of carbon by subduction, the difference is added to the continental crust. If the volcanic carbon enters the oceans organic precipitation creates carbonates. If the volcanic carbon enters the atmosphere it enters the continental crust by the Urey reaction. Current estimates of carbon fluxes from and to the mantle are sufficient to have produced all the carbon in the continental crust. At the present time, it is not possible to quantify the relative importance of carbon addition to the continental crust from the early atmosphere and the mantle.

\section{IMPLICATIONS}

We have addressed two major questions concerning carbon in the atmosphere in this paper. The first is the origin of the carbon in the continental crust. We conclude that it is possible the car- bon could have been extracted either from the early atmosphere or from the mantle over a longer period of time. Studies of the concentration of carbon in the atmosphere and continental crust over geologic time are required and should receive a high priority.

The second question we have addressed is the relaxation of injections of carbon into the atmosphere back to equilibrium values. We quantify this by studying the Paleocene-Eocene thermal maximum (PETM). This has obvious implications for the recovery from the process of anthropogenic injection of carbon into the atmosphere. We find the relaxation time to be about 50000 years.

\section{ACKNOWLEDGMENT}

It is with great sadness that we note the death of Louise Kellogg on April 14, 2019.

\section{REFERENCES CITED}

Berner, R.A., and Caldeira, K. (1997) The need for mass balance and feedback in the geochemical carbon cycle. Geology, 25, 955-956.

Berner, R.A., and Kothavala, Z. (2001) GEOCARB III: A revised model of atmospheric $\mathrm{CO}_{2}$ over Phanerozoic time. American Journal of Science, 301, 182-204.

Blättler, C.L., and Higgins, J.A. (2017) Testing Urey's carbonate-silicate cycle using the calcium isotopic composition of sedimentary carbonates. Earth and Planetary Science Letters, 479, 241-251.

Dasgupta, R., and Hirschmann, M.M. (2010), The deep carbon cycle and melting in Earth's interior. Earth and Planetary Science Letters, 298, 1-13.

DePaolo, D.J. (2015) Sustainable carbon emissions: The geologic perspective. MRS Energy \& Sustainability, 2, E9.

Frezzotti, M.L., Selverstone, J., Sharp, Z.D., and Compagnoni, R. (2011) Carbonate dissolution during subduction revealed by diamond-bearing rocks from the Alps. Nature Geoscience, 4, 703-706.

Gutjahr, M., Ridgwell, A., Sexton, P.F., Anagnostou, E., Pearson, P.N., Pälike, H., Norris, R.D., Thomas, E., and Foster, G.L. (2017) Very large release of mostly volcanic carbon during the Palaeocene-Eocene thermal maximum. Nature, 548, 573-577.

Hayes, J.M., and Waldbauer, J.R. (2006) The carbon cycle and associated redox processes through time. Philosophical Transactions of the Royal Society of London B: Biological Sciences, 361, 931-950.

Houghton, R.A. (2007) Balancing the global carbon budget. Annual Review of Earth and Planetary Sciences, 35, 313-347.

Kasting, J.F., and Ackerman, T.P. (1986) Climatic consequences of very high carbon dioxide levels in the Earth's early atmosphere. Science, 234, 1383-1386.

Kelemen, P.B., and Manning, C.E. (2015) Reevaluating carbon fluxes in subduction zones, what goes down, mostly comes up. Proceedings of the National Academy of Sciences, 112, E3997-E4006.

Kramers, J.D. (2002) Global modelling of continent formation and destruction through geological time and implications for $\mathrm{CO}_{2}$ drawdown in the Archaean eon. Geological Society, London, Special Publications, 199, 259-274.

Lowe, D.R., and Tice, M.M. (2004) Geologic evidence for Archean atmospheric and climatic evolution: Fluctuating levels of $\mathrm{CO}_{2}, \mathrm{CH}_{4}$, and $\mathrm{O}_{2}$ with an overriding tectonic control. Geology, 32, 493-496.

McInerney, F.A., and Wing, S.L. (2011) The Paleocene-Eocene thermal maximum: A perturbation of carbon cycle, climate, and biosphere with implications for the future. Annual Review of Earth and Planetary Sciences, 39, 489-516.

Royer, D.L. (2014). Atmospheric $\mathrm{CO}_{2}$ and $\mathrm{O}_{2}$ during the Phanerozoic: Tools, patterns, and impacts. Treatise on Geochemistry, 2nd ed. vol. 6, pp. 251-267.

Rye, R., Kuo, P.H., and Holland, H.D. (1995) Atmospheric carbon dioxide concentrations before 2.2 billion years ago. Nature, 378, 603-605.

Storey, M., Duncan, R.A., and Swisher, C.C. (2007) Paleocene-Eocene thermal maximum and the opening of the northeast Atlantic. Science, 316, 587-589.

Urey, H.C. (1952) On the early chemical history of the earth and the origin of life. Proceedings of the National Academy of Sciences, 38, 351-363.

(1956) Regarding the early history of the earth's atmosphere. Geological Society of America Bulletin, 67, 1125-1128.

Wedepohl, K.H. (1995) The composition of the continental crust. Geochimica et Cosmochimica Acta, 59, 1217-1232.

MANUSCRIPT RECEIVED NOVEMBER 6, 2018

MANUSCRIPT ACCEPTED JUNE 24, 2019

MANUSCRIPT HANDLED BY JIE LI 